\title{
HEPATOTOXICITY AND ASSOCIATED RISK FACTORS IN HIV-INFECTED PATIENTS RECEIVING ANTIRETROVIRAL THERAPY AT FELEGE HIWOT REFERRAL HOSPITAL, BAHIRDAR, ETHIOPIA
}

\author{
Wondemagegn Mulu ${ }^{1}$ Bokretsion Gidey ${ }^{2}$, Ambahun Chernet ${ }^{2}$, Genetu Alem², \\ Bayeh Abera ${ }^{1}$
}

ABSTRACT

BACKGROUND: In Human Immunodeficiency Virus (HIV) infected patients on antiretroviral treatment (ART), hepatotoxicity is life threatening. Its outcome may lead to liver failure and death. This study was conducted to determine the rate and determinants of elevated alanine amino transferase (ALT) (referred as $>40 I U / L$ for both males and females).

METHODS: A cross sectional study was conducted on HIV infected individuals who are on ART and suspected of drug resistance at Felege Hiwot Referral Hospital, Bahir Dar from July to December 2012. Venous bloods were collected from each patient and processed parallely to determine ALT, number of HIV RNAs, CD4 and CD8 T cells count, anti hepatitis $C$ virus $(H C V)$ and hepatitis $B$ surface antigen.

RESULTS: Out of 269 HIV infected patients receiving ART, 32\% were confirmed of grades 1-4 levels of elevated ALT. The rate of severe hepatotoxicity (grade 3 and 4) was 1.84\%. Patients with increased CD8 $T$ cell counts $(P=0.011 ; A O R=1.82 ; C I: 1.12-2.54)$, alcohol over use $(P=0.014 ; A O R=1.23 ; C I$ : 1.363.29) and detectable HIV-1 RNA copies (P=0.015; AOR=2.07; CI: 1.15-3.74) independently predicts the elevation of ALT.

CONCLUSIONS: In HIV infected patients on ART, extreme elevations of ALT were infrequent but minor elevations were common so that patient-linked variables such as use of alcohol intake must be taken in to account for better clinical management of ART patients. The role of active HCV co-infection on the treatment outcome of ART should be further studied.

Key words: ALT, HIV, ART, Bahir Dar, Ethiopia

DOI : http://dx.doi.org/10.4314/ejhs.v23i3.4

\section{INTRODUCTION}

Highly active antiretroviral therapy (HAART) in Human Immuno Deficiency Virus (HIV) infected patients has led to dramatic improvements in the survival of patients in resource-limited settings (1). However, antiretroviral drugs have been associated with both short and long-term toxicities including hepatotoxicity, which may be life threatening (1). Elevations in serum hepatic enzymes have been described in association with all major classes of antiretroviral therapy (ART) (2). However, the complexity of medication used in antiretroviral therapy complicates the understanding of the independent effects of each drug in the development of drug induced liver injury (2, 3). Therefore, prevention and management of antiretroviral therapy related toxicity has emerged as a major issue for HIV/ AIDS treatment and care (4). The pathogenesis of drug-induced liver disease normally involves

${ }^{1}$ Department of Medical Microbiology, Immunology and Parasitology, Bahirdar University, Ethiopia

${ }^{2}$ Bahir Dar Regional Health Bureau Laboratory Center, Bahirdar, Ethiopia

Corresponding Author: Wondemagegn Mulu, Email: wondem-32@yahoo.com 
the participation of the parent drug or its metabolite that either affects the cell biochemistry directly or indirectly by eliciting an immune response (6). As HIV-infected patients live longer, they develop long term manifestations of chronic HIV infection and treatment complication (6). The severity of ART may range from the absence of symptoms to liver decomposition and the outcome ranges from spontaneous resolution to liver failure and death (7).

Alanine aminotransferase and Aspartate aminotransferase are hepatic enzymes that could be used as markers of hepatocellular injury (8). Studies have revealed that $14-20 \%$ of adults on ART had elevated serum liver enzymes as a marker of hepatocellular injury (9). Liver enzyme elevations (LEEs) are frequently associated with use of potent antiretroviral combination therapy. The most well-established risk factors for LEEs are chronic hepatitis $\mathrm{B}$ and $\mathrm{C}$ infections $(3,10)$. In addition, several other parameters (e.g., a greater increase in CD4 cell count after the start of antiretroviral therapy and higher baseline levels of alanine aminotransferase (ALT), systemic opportunistic infections, cirrhosis, alcohol or drug induced hepatotoxicity, age and gender $(11,12)$ are risk factors for LEEs.

In 2003, Ethiopia defined and included first and second line drug regimens in the national treatment guidelines, including different HIV-drug combinations based on World Health Organization (WHO) recommendations and in July 2004, the number of people who had been taking ART was 10,400 (13). There is paucity of information on the extent and risk factors for ART related hepatotoxicity associated with the concentration of HIV-1 viral load, HIV co-infections with hepatitis $\mathrm{C}$ and $\mathrm{B}$ viruses in Ethiopia especially at Felege Hiwot Referral Hospital. Thus, the purpose of this study was to determine serum alanine aminotransferase levels as markers of hepatotoxicity in HIV-infected patients receiving ART associated with risk factors such as concentration of HIV RNA copies (viral load), hepatitis $\mathrm{C}$ and $\mathrm{B}$ virus co-infections and CD4 and CD8 T cells.

\section{METHODS AND PARTICIPANTS}

A hospital based cross sectional study among HIV infected patients on ART and suspected of drug resistance was conducted from July to December 2012 at Felege Hiwot Referral Hospital, Bahir Dar, Northwest Ethiopia. The hospital has 273 beds offering different specialized services including ART services in its ART clinic (14). Felege-Hiwot Referral Hospital is one of the government-sponsored ART centers at Bahir Dar Town. The ART clinic provides follow-up service for pre-ART patients and patients who are on ART to both pediatrics and adults by specialists and trained health professionals. It provides the ART service for those HIV patients who are found in Bahir Dar and its vicinity. In addition, the hospital accepts ART referred patients from different parts of the region (15).

A structured questionnaire was used for collection of data on socio-demographic characteristics and other associated risk factors such as WHO categories of the patient, history of current tuberculosis treatment and use of alcohol. A total of 269 HIV infected patients receiving antiretroviral therapy during the study period were included conveniently. Number of HIV RNA copies, level of alanine aminotransferase, CD4 and CD8 lymphocyte count, anti HCV and HBsAg detection were done during the time of viral load detection for antiretroviral regimen change.

Ten $\mathrm{ml}$ of venous blood was collected using K3 EDTA on vacutainer tube from each participant. From this $10 \mathrm{ml}, 50 \mu 1$ of blood was taken for CD4 and CD8 $\mathrm{T}$ cells count. The remaining amount of venous blood was used for the preparation of serum and plasma for the analysis of serum ALT and HIV RNA copies; 4 $\mathrm{ml}$ of EDTA anticoagulated blood was taken and allowed to stand a certain period of time and then centrifuged to obtain the plasma.

Simultaneously, another $4 \mathrm{ml}$ of blood was taken and allowed to coagulate after which it was centrifuged at $3000 \mathrm{rpm}$ for 5 minutes to obtain sera. The level of alanine amino transferase (ALT) was measured on a Beckman Coulter Synchron Clinical Systems auto lab Analyzer (Beckman Coulter Inc. Fullerton, CA, USA). Specifically, ALT was measured using a pyruvate/lactate dehydrogenase method. The test was carried out using the mono reagent procedure. The working reagent was prepared by mixing 4 volumes of reagent one (R1) in 1 volume of reagent two (R2). The auto lab analyzer was calibrated for ALT. A series of labeled test tubes, 
i.e. Blank, normal control and patients from 1, $2 \ldots . n^{\text {th }}$ were used according to the number of samples to be analyzed. The preparation was mixed and the first reading of absorbance was executed after 90 seconds at $37^{\circ} \mathrm{C}$. The change in absorbance per minute was then calculated. Normal value for ALT (SGPT) at $37^{\circ} \mathrm{C}$ : 0- 40 IU/L was taken for both Women and Men.

For the determination of HIV RNA copies, $200 \mu \mathrm{l}$ of plasma was prepared from K3 EDTA collected tube and samples extracted automatically using Abbott Real Time HIV-1 assay (Abbott Molecular Inc., Des Plaines, IL, USA) as per manufacturer's instructions. The extracted samples were amplified and detected on the $\mathrm{m}$ $2000 \mathrm{rt}$ platforms according to the manufacturers instruction. The result of the finding was interpreted as: detectable (RNA copies > 150 copies/ $\mathrm{ml}$ of blood), detectable but under lower detection limit (RNA copies of < 150) and nondetectable (Target value was not detected within the given sample).

Absolute CD4 and CD8 T cells count was performed using a specific monoclonal antibody and fluorescence-activated cell sorting (FACS count) (BECTON DJCKINSON, USA) which is a single platform. According to the manufacturer's instruction, 50 $\mu$ l of whole blood from k3 EDTA collected tube was added using an automated electronic pipette to each tube provided. The tubes were vortexed upside down then upright for 5 seconds and incubated for 60-120 minutes in the dark at room temperature. Then $50 \mu$ l of fixative solution provided in the reagent kit was added into each tube after the tubes were vortexed, stained samples were analyzed by the FACS count double tube software.

Serological assay for the presence of hepatitis B surface antigens (HBsAg) was performed on sera using EILSA, (Linear chemicals, Joaquim Costa, Barcelona, Spain) according to the manufacturer's manual instructions. Similarly, IgG and IgM antibodies to HCV were detected using ELISA, (Linear chemicals, Joaquim Costa, Barcelona, Spain).

Data were entered and analyzed using SPSS version 16 software. Independent sample $T$ test was used for group mean comparison of CD4 T cell counts. Pearson $\chi^{2}$ test and bivariate were used for categorical data to generate $\mathrm{P}$-values and $\mathrm{P}$-value $<0.05$ was considered statistically significant. Multivariate logistic regression analysis was done to identify the independent determinant factors of ALT elevations. The study was approved by the Research and Ethical Committee of Bahir Dar University and written informed consent was obtained from each study participant.

The following WHO operational definitions were used:

Toxicity of degree 0 : the level of toxicity which is considered as normal in which its value is $>1.25 \mathrm{x}$ normal value of ALT in serum

Toxicity of degree 1: the Level of toxicity which is considered as weak in which its value is 1.256 - $2.5 \mathrm{x}$ normal value of ALT in serum

Toxicity of degree 2: the Level of toxicity which is considered as moderate in which its value is 2.6 $-5 \mathrm{x}$ normal value of ALT in serum

Toxicity of degree 3: the Level of toxicity which is considered as severe in which its value is $5.1-$ $10 \mathrm{x}$ normal value of ALT in serum

Toxicity of degree 4: the Level of toxicity which is considered as severe in which its value is $>10$ $\mathrm{x}$ normal value of ALT in serum

No alcohol intake: For those patients who never had a habit of drinking alcohol

Moderate alcohol intake: drinking weekly and less than 5 drinks per occasion

Heavy alcohol intake: drinking weekly and $\geq 5$ drinks per occasion

\section{RESULTS}

A total of 269 HIV infected patients receiving ART were included in this study. Of these, 137 (51\%) were males and 132 (49\%) females with a median age of 35 , ranging from 11 to 75 years. Among the 269 study participants, 233 (86.6\%) were urban dwellers while $36(13.4 \%)$ were from rural areas (Table 1). According to the World Health Organization (WHO) category of HIV stages, the majority (71.4\%) of HIV-infected patients were in stage III whereas $9.7 \%$ were in stage IV (Table 4). The overall prevalence of hepatotoxicity (alanine aminotransferase elevation) in HIV-infected patients receiving ART was $32 \%$. The hepatotoxicity rate was similar between males (32\%) and females (31.8\%) $(\mathrm{P}=0.958)$. Statistically significant association was not observed among the different age groups $(\mathrm{P}=0.748)$. The rate of alanine aminotransferase 
elevation was higher in HIV ART patients living

in rural areas $(44 \%)$ than urban residents $(30 \%)$

(Table1).

Table 1: Alanine amino transferase elevations in relation to sex, age and residence groups of HIV infected ART patients at FHRH, Bahir Dar,July - December, 2012

\begin{tabular}{|c|c|c|c|c|}
\hline \multirow[t]{2}{*}{$\begin{array}{l}\text { Demographic } \\
\text { characters }\end{array}$} & \multicolumn{3}{|c|}{ Alanine amino transferase status } & \multirow[t]{2}{*}{ P - value } \\
\hline & $\begin{array}{l}\text { Elevated } \\
\text { No. }(\%)\end{array}$ & $\begin{array}{l}\text { Not elevated } \\
\text { No. }(\%)\end{array}$ & $\begin{array}{l}\text { Total } \\
\text { No. }(\%)\end{array}$ & \\
\hline \multicolumn{5}{|l|}{ Sex } \\
\hline Male & $44(32)$ & $93(68)$ & $137(51)$ & 0.958 \\
\hline Female & $42(31.8)$ & $90(68.2)$ & $132(49)$ & \\
\hline Total & $86(32)$ & $183(68)$ & $269(100)$ & \\
\hline \multicolumn{5}{|l|}{ Age in years } \\
\hline $10-20$ & $3(30)$ & $7(70)$ & $10(3.7)$ & \\
\hline $21-30$ & $28(33.3$ & $56(66.7)$ & $84(31.2)$ & \\
\hline $31-40$ & $31(29.5)$ & $74(70.5)$ & $105(39$ & \\
\hline $41-50$ & $18(29.5)$ & $33(70.5)$ & $51(19)$ & 0.748 \\
\hline$\geq 51$ & $6(31.6)$ & $13(68.4)$ & $19(7.1)$ & \\
\hline$\overline{\text { Total }}$ & $86(32)$ & $183(68)$ & $269(100)$ & \\
\hline \multicolumn{5}{|l|}{ Residence } \\
\hline Urban & $70(30)$ & $163(70)$ & $233(86.6)$ & 0.086 \\
\hline Rural & $16(44.4)$ & $20(55.6)$ & $36(13.4)$ & \\
\hline Total & $86(32)$ & $183(68)$ & $269(100)$ & \\
\hline
\end{tabular}

From 269 HIV infected patients on ART, 86 (32\%) developed grade 1- 4 levels of toxicity, of which $60(22.3 \%)$ was grade 1 levels, $21(7.8 \%)$ grade 2 levels and $3(1.1 \%)$ and $2(0.74 \%)$ were grade 3 and 4 levels of toxicity respectively (Figure 1).

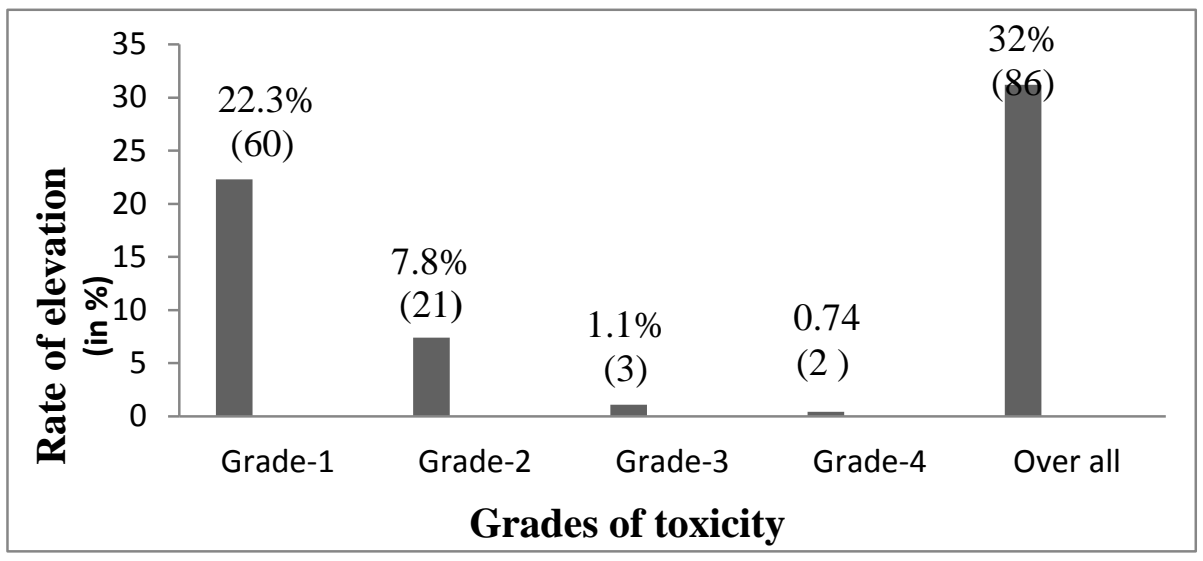

Figure 1: Frequency of grades of alanine amino transferase elevations in HIV infected patients on ART at FHRH, Bahir Dar, July - December, 2012.

Of the 269 ART patients who participated with known HBV/HCV serology, 30 (11.2\%) were HBsAg positive, 51 (18.96\%) were anti-HCV positive and $8(3 \%)$ were both HBsAg and anti-
HCV positive (Table 2). Ten out of 30 (45\%) and 18 out of $51(33 \%)$ of the patients who were $\mathrm{HBsAg}$ positive or anti-HCV positive, 
respectively, showed elevated levels of alanine amino transferase. Out of eight patients who tested positive for both HBsAg and anti-HCV 4 (50\%) develop alanine amino transferase elevation.
However, the difference was not statistical significant (Figure 2).

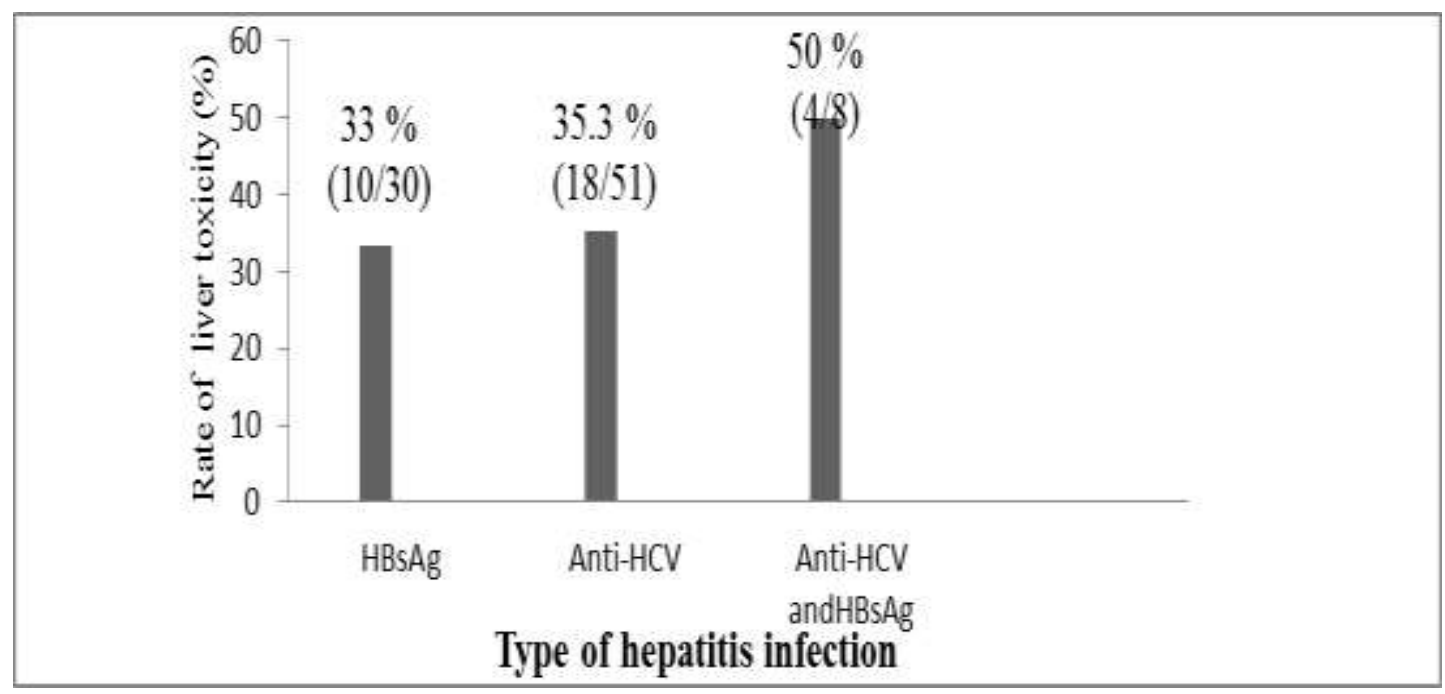

Figure 2: Rate of liver toxicity among hepatitis $\mathrm{C}$, hepatitis $\mathrm{B}$ virus and both hepatitis $\mathrm{B}$ and $\mathrm{C}$ co infected ART patients at FHRH, Bahir Dar, July - December, 2012.

The rate of liver enzyme elevation among patients who had their viral load was detected, undetected and under lower detection limit was 42 (39.3\%), $38(29.2 \%)$ and $6(19.4 \%)$ respectively. In the case of liver toxicity, statistically significant association was observed between patients having detected viral load and non-detected viral load $(\mathrm{P}=0.046)$ using chi-square test. Significant association between hepatitis virus co-infection (HCV, HBV) and rate of ALT elevation were not observed (Table 2).

The rate of ALT elevations did not show statistically significant association $(\mathrm{P}=0.463)$ among patients who have a CD4 $\mathrm{T}$ cell value ranged from 0-499 cells $/ \mathrm{mm}^{3}$ (32.3\%), 500-1300 cells $/ \mathrm{mm}^{3}(25.8 \%)$ and $\geq 1301$ cells $/ \mathrm{mm}^{3}(50 \%)$ respectively. However, the rate of ALT elevation among patients who have a CD8 $\mathrm{T}$ cell value ranged from 0-319 cells $/ \mathrm{mm}^{3}, 320-1800$ cells $/ \mathrm{mm}^{3}$ and $\geq 1800$ cells $/ \mathrm{mm}^{3}$ were $13(28.3 \%), 46$ $(27.3 \%)$ and $26(49.1 \%)$ respectively and the difference was statistically significant $(\mathrm{P}=0.011)$. The proportion of ALT elevation among heavy alcohol user was 7(41.2\%). This was much higher than those who did not receive any alcohols 45/174 (25.9\%) ( $\mathrm{P}=0.011)$ (Table 2).

Increasing the mean CD4 $\mathrm{T}$ cell count was not a determinant factor for the elevation of alanine aminotransferase. Statistically significant association was found between increased mean of CD8 $\mathrm{T}$ cell count and liver toxicity (Table 3 ). Of the 269 study participants, 78 (29\%) were treated for pulmonary tuberculosis. Tuberculosis treated patients had higher glutamic pyruvate transaminase (GPT) mean value (40.3) than the non- treated group (35.1) $(\mathrm{P}=0.02)$ (Table 4). 
Table 2: The risk factor analysis to rate of alanine aminotransferase elevations among the total study participants at FHRH, Bahir Dar, July - December, 2012.

\begin{tabular}{|c|c|c|c|c|}
\hline \multirow{2}{*}{ Potential risk factors } & \multicolumn{3}{|c|}{ Alanine amino transferase } & \multirow{2}{*}{ P-value } \\
\hline & $\begin{array}{l}\text { Elevated } \\
\text { No. }(\%)\end{array}$ & $\begin{array}{l}\text { Not elevated } \\
\text { No. }(\%)\end{array}$ & $\begin{array}{l}\text { Total } \\
\text { No. }(\%)\end{array}$ & \\
\hline \multicolumn{5}{|l|}{ HIV RNA level } \\
\hline Detected & $42(39.3)$ & $65(60.7)$ & $107(39.9)$ & 0.046 \\
\hline Undetected & $38(29.2)$ & $92(70.8)$ & $130(48.5)$ & \\
\hline $\begin{array}{l}\text { Under lower detection } \\
\text { limit }\end{array}$ & $6(19.4)$ & $25(80.6)$ & $31(11.6)$ & \\
\hline \multicolumn{5}{|l|}{ Number of CD4 T cell } \\
\hline $0-499$ cells $/ \mathrm{mm} 3$ & $76(32.3)$ & $159(67.7)$ & $235(87.7)$ & 0.463 \\
\hline $500-1300$ cells $/ \mathrm{mm} 3$ & $8(25.8)$ & $23(74.2)$ & $31(11.6)$ & \\
\hline$\geq 1301 \mathrm{cells} / \mathrm{mm} 3$ & $1(50)$ & $1(50)$ & $2(0.75)$ & \\
\hline \multicolumn{5}{|l|}{ Number of CD8 T cells } \\
\hline $0-319$ cells $/ \mathrm{mm} 3$ & $13(28.3)$ & $33(71.7)$ & $46(17.2)$ & \\
\hline $320-1800$ cells $/ \mathrm{mm} 3$ & $46(27.3)$ & $122(72.6)$ & $168(62.9)$ & 0.011 \\
\hline$\geq 1801 \mathrm{cells} / \mathrm{mm} 3$ & $26(49.1)$ & $27(50.9)$ & $53(19.8)$ & \\
\hline \multicolumn{5}{|l|}{ CD4/ CD8 ratio } \\
\hline $0.0-0.49$ cells $/ \mathrm{mm} 3$ & $76(32.2)$ & $160(67.8)$ & $236(87.7)$ & 0.878 \\
\hline $0.5-2.1$ cells $/ \mathrm{mm} 3$ & $10(30.3)$ & $23(69.7)$ & $33(12.3)$ & \\
\hline \multicolumn{5}{|l|}{ Alcoholism } \\
\hline No intake & $45(25.9)$ & $129(74.1)$ & $174(64.7)$ & 0.012 \\
\hline Moderate intake & $34(43.6)$ & $44(56.4)$ & $78(30)$ & \\
\hline Heavy intake & $7(41.2)$ & $10(58.8)$ & $17(6.3)$ & \\
\hline \multicolumn{5}{|l|}{ Anti-HCV } \\
\hline Positive & $18(35.3)$ & $33(64.7)$ & $51(32)$ & 0.341 \\
\hline Negative & $68(31.2)$ & $150(68.8)$ & $218(68)$ & \\
\hline \multicolumn{5}{|l|}{ Both Anti-HCV and } \\
\hline HBsAg & $4(4.7)$ & $82(95.3)$ & $86(32.1)$ & 0.507 \\
\hline Positive & $4(2.2)$ & $179(97.8)$ & $183(67.9)$ & \\
\hline \multicolumn{5}{|l|}{ Negative } \\
\hline HBsAg & $10(33.3)$ & $20(66.7)$ & $30(11.2)$ & 0.270 \\
\hline Positive & $76(31.8)$ & $183(68.2)$ & $239(88.8)$ & \\
\hline Negative & $86(32)$ & $203(75.5)$ & $269(100)$ & \\
\hline Total & & & & \\
\hline
\end{tabular}

Table 3: Hepatotoxicity among HIV infected patients on ART with the CD4 and CD8 T cell count at FHRH, Bahir Dar,*- July - December, 2012.

\begin{tabular}{lllllll}
\hline Liver toxicity & $\begin{array}{l}\text { Mean of CD4 } \\
\text { T cell count/mm3 }\end{array}$ & P-value & $\begin{array}{l}\text { Mean of CD8 } \\
\text { T cell count/mm3 }\end{array}$ & \multicolumn{3}{c}{$\begin{array}{c}\text { CD4:CD8 } \\
\text { ratio }\end{array}$} \\
& & & P - value & & P - value \\
\hline Elevated & 245 & 0.811 & 100 & 0.01 & 0.26 & 0.406 \\
Not elevated & 248 & & 868 & & 0.29 & \\
\hline
\end{tabular}


Table 4: Mean of SGPT with the current Tuberculosis therapy and WHO stages among HIV infected patients that are on ART at FHRH, Bahir Dar, July - December, 2012.

\begin{tabular}{llll}
\hline Variables & $\begin{array}{l}\text { Frequency } \\
\text { No. }(\%)\end{array}$ & SGPT Mean & P-value \\
\hline TB treatment status & $78(29)$ & 40.3 & 0.021 \\
Currently TB treated & $191(71)$ & 35.1 & \\
Currently TB untreated & & 30.8 & \\
WHO stages & $18(6.7)$ & 39.4 & 0.204 \\
I & $33(12.3)$ & 37.4 & \\
II & $192(71.4)$ & 30.6 & \\
III & $26(9.7)$ & & \\
IV & & & \\
&
\end{tabular}

WHO, World Health Organizations; TB, Tuberculosis, SGPT, Serum glutamate pyruvate transaminase

Socio demographic variables, hepatitis $\mathrm{C}$ and $\mathrm{B}$ virus co-infections and those variables that showed significance in the bivariate analysis at levels of less than or equal to 0.2 were included in the multivariate analysis. From this variables, only the presence of detectable amount of HIV RNA copies $(\mathrm{P}=0.015 ; \mathrm{AOR}=2.07 ; \mathrm{CI}: 1.15-3.74)$, over use of alcohol $(\mathrm{P}=0.014 ; \mathrm{AOR}=1.23$; CI: 1.36-3.29) and an increased CD8 $\mathrm{T}$ lymphocytes $(\mathrm{P}=0.012, \quad \mathrm{AOR}=1.82 ; \quad \mathrm{CI}: \quad 1.12-2.54)$ independently predicts the elevated level of alanine amino transferase (Table 5).

Table 5: Multivariate analysis of risk factors for grade 1- 4 hepatotoxicity in HIV-1 infected patients while receiving concomitant antiretroviral therapy at FHRH, Bahir Dar, July - December, 2012.

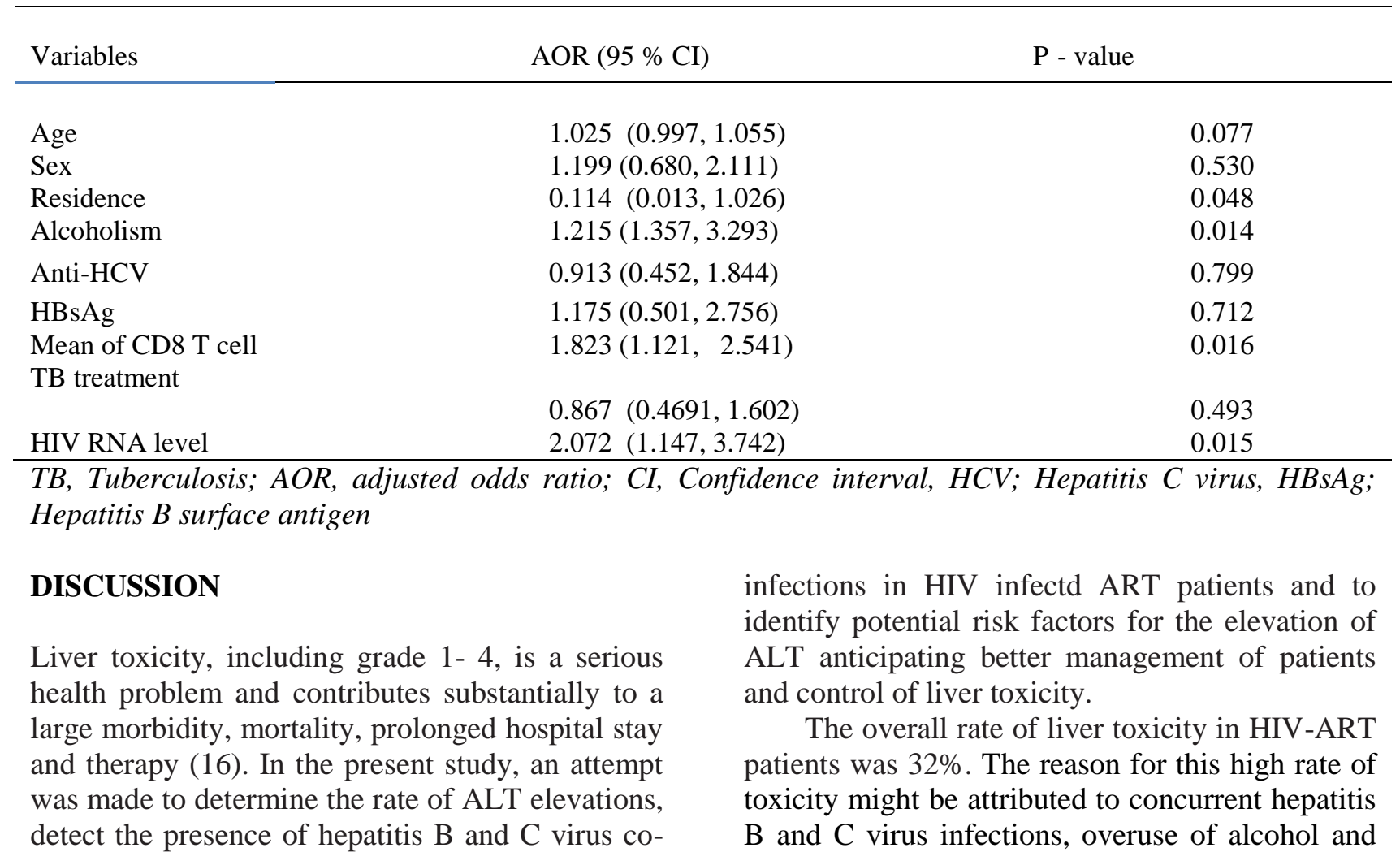


other medical conditions. This finding is comparable with findings of similar studies conducted elsewhere by Mankhatithan et al (2), Crumciaflone et al (17) where the rate of grade 1- 4 toxicity were $31.4 \%$ and $27 \%$ respectively. However, our finding differs from studies carried out in other countries such as South Africa (18), Cameron (19) and France (20) where elevation rate of $23 \%, 22.6 \%$ and $20.9 \%$ were reported respectively. The difference could be due to the higher prevalence of hepatitis $\mathrm{B}$ and $\mathrm{C}$ coinfections in our patients compared to those of the other studies.

In the present study, severe hepatotoxicity (grade 3 or 4 as defined by the WHO) was observed in $1.84 \%$ of the study participants. This finding is consistent with other studies carried out in Uganda (1) and Thailand (4) that showed $2.9 \%$ and $1.3 \%$ of severe hepatotoxicity respectively. However, very high rate of severe hepatotoxicity was reported in other studies conducted on HIV infected ART patients by Sulkowski et al (3) and Mankhatithan et al (2) that indicated $10.4 \%$ and $17.7 \%$, respectively. The wide variations in the rate of severe hepatotoxicity reported in our study and previous studies is probably because of differences in the population characteristics, different definitions of severe hepatotoxicity and the frequency of patient follow-up, monitoring and duration of therapy.

Sex difference has not been found to be a determinant factor for elevated ALT $(\mathrm{P}=0.958)$. This is probably because the courses of HIV pathogenesis and drug metabolism in humans generally are not sex dependent. This finding is similar with the findings of previous studies carried out in different countries such as Nigeria (6), Cameron (20), South Africa (21), Swiss (22) and Brazil (23). As found out in this study, age difference is not also a determinant factor for liver enzyme elevations. This could be due to the fact that more than $90 \%$ of the cases were individuals up to 50 years of age. There are also studies which support that age is not a risk factor for development of hepatotoxicity in patients taking ART drugs $(22,24,25)$. However, there are also studies which support that age $>50$ years is a risk factor for hepatotoxicity in patients taking ART drugs.

In this study, a higher ALT elevation was revealed in HIV-ART patients co-infected with
$\mathrm{HCV}(35.3 \%)$ compared to the mono-HIV infected group (31.2\%). However, unlike other authors such as Mankhatithan et al (2), Livry et al (18) and Yimer et al (24), we did not find statistically significant differences $(\mathrm{P}=0.799$, $\mathrm{AOR}=0.913, \mathrm{CI}=0.452-1.844)$. The possible reason for the observed difference might be that some of the HCV infections may not be at active (replicated) stage because we did not identify active HCV co-infections because we detect the antibody rather than the antigen. In this study, no difference of rate of hepatotoxicity observed between HBV co-infected $(33.3 \%)$ and mono HIV infected group (31.8\%). However, our finding contradicts with findings of Mankhatithan et al in South East Asian (2), Livry et al in France (18) and Gisolf et al in Belgium (25) that reported co-infection with HBV was a risk factor.

In unadjusted analyses, detectable HIV RNA copies or a high HIV RNA load was associated with the rate of liver toxicity in these study $(\mathrm{P}=0.015, \quad \mathrm{AOR}=2.072, \quad \mathrm{CI}=1.147-3.742)$ as indicated by other studies carried out in Swiss by kovari et al (22) and by Forrester et al (26). This might be because higher levels of HIV RNA copies would lead to greater rates of apoptosis and necroinflammatory activity. Such apoptosis and necroinflammatory activity could be expected to elevate liver enzymes in a manner dependent on HIV viral load as it was explained by Forrester et al (26).

A statistically significant association was found between increased CD8 lymphocyte count and rate of ALT elevations. This might be due to the presence of an immunologic mechanism for the development of hepatotoxicity. The other possible explanations might be that patients with low CD4 and increased CD8 lymphocyte counts are more prone in acquiring opportunistic infections-this might necessitate consumption of different drugs leading to subclinical liver damage and there by increased susceptibility for liver enzyme elevations while taking anti HIV as indicated by Yimer et al in Ethiopia (24).

Overuse of alcohol $(\mathrm{P}=0.014)$ has been found to be a risk factor in this study. The same is true in studies carried out by kovari et al (22). The high rate of elevated ALT among alcohol over user patients might be due to the direct hepatocellular damaging effect of the alcohol that will leads to release of ALT from liver cells. Importantly, on 
bivariate analysis, we found out a statistically significant association between previous tuberculosis treatment $(\mathrm{P}=0.01)$ and rate of alt elevations. However, on multivariate analysis, we did not find associations between hepatotoxicity and tuberculosis therapy $(\mathrm{P}=0.493)$.

In conclusion, the rate of elevated ALT identified in this study, was high. The occurrence of an elevated alanine amino transferase is independently influenced by overuse of alcohol, history of tuberculosis therapy and the presence of detectable number of HIV RNA. Therefore, patient-linked variables must be taken into account for better clinical management of HIV infected ART patients. HCV co-infections need to be taken into account in the management of HIV-infected patients, in particular when the initiation of antiretroviral therapy is considered. Further study on the role of active $\mathrm{HCV}$ co infection on the treatment outcome of ART and rate of hepatotoxicity from onset of ART and the role of the individual antiretroviral drugs to elevation of ALT should be done.

The study has some limitations, however. The relation of liver toxicity with the onset or duration of ART has not been done. We also carried out detection of anti $\mathrm{HCV}$ rather than detecting its antigen as a result we did not identify whether the infection was active or chronic, and the involvement of the type of regimen to the elevation of alanine aminotransferase were not conducted.

\section{ACKNOWLEDGMENTS}

We would like to express special thanks to Bahir Dar University for financing this research. We are also indebted to Bahir Dar Regional Health Research Laboratory Center for providing ALT, CD4 and CD8 reagents and for using their laboratory setup. Finally, we would like to thank all the study participants.

\section{REFERENCES}

1. Kalyesubula R, Kagimu M, Opio KC et al. Hepatotoxicity from first line antiretroviral therapy: an experience from a resource limited setting. Afr Health Sc. 2011; 11: 16 - 23.

2. Mankhatithan W, Lueangniyomkul A, Manosuthin W. Hepatotoxicity in patients co- infected with tuberculosis and HIV-1 while receiving non-nucleoside reverse transcriptase inhibitors based antiretroviral therapy and rifampicin containing antituberculosis drugs. Southeast Asian Jtrop Med Public Health. 2011; 429: 651-658.

3. Sulkowski MS. Drug-induced liver injury associated with antiretroviral therapy that includes HIV-1 protease inhibitors. Clin Infect Dis. 2004; 38: 90-97.

4. Law WP, Dore GJ, Duncombe CJ et al. Risk of severe hepatotoxicity associated with antiretroviral therapy in the HIV-NAT Cohort, Thailand, 1996-2001. AIDS. 2003; 17:21912199.

5. Montessori V, Press N, Harris M, Akagi L, Montaner JS. Adverse effects of antiretroviral therapy for HIV infection. CMAJ. 2004; 170: 229-238.

6. Emejulu AA, Ujowundu CO, Igwe CU et al. Hepatotoxicity of antiretroviral drugs in HIV sero positive Nigerian Patients. Aust J Basic and App Sci. 2010; 4: 4275-4278.

7. Eluwa G, Badru T, Akpoigbe KJ. Adverse drug reactions to antiretroviral therapy (ARVS): incidence, type and risk factors in Nigeria. 2012; 12: 1-9. BMc Clin Pharmacol. 2012; 12: 1- 9 .

8. Zechini B, Pasquazzi Z, Aceti A. Correlation of serum aminotransferase with HCV RNA levels and histological finding in patients with chronic hepatitis $\mathrm{C}$ : The role of serum Aspartate transaminase in the elevation of disease progression. Eur $J$ Gastroenterol Hepatol. 2004, 16: 91- 96.

9. Puoti M, Nasta P, Gatti F et al. Care -related liver disease: ARV drugs, co - infection, and other risk factors. JIAPAC. 2009; 8: 30-42.

10. Shores NJ, Madia I, Perez-Saleme L, Nuuez M. Virological rather than host factors are associated with transaminase levels among HIV/HCV co-infected patients. Jint Assoc pjysicians AIDS care. 2010; 9: 15-19.

11. Joshi D, Grady JO, Dietrich D, Gazzard $B$, Agrawal K. Increasing burden of liver disease in patients with HIV infection. Lancet. 2011; 377: 1198-1209.

12. Kontorinis N, Dieterich D. Hepatotoxicity of antiretroviral therapy. AIDS Rev. 2003; 5: 3643. 
13. MOH. Guide lines for implementation of antiretroviral therapy in Ethiopia. 2005

14. FGAE. Factors affecting accessibility and acceptability of VCT services in Bahir Dar. Family guidance association of Ethiopia, North Western branch. 2001; 1-54.

15. Abera B, Wall F, Tewabe T, Alem A, Yassin M. ART- naïve HIV patients at Felege hiwot referral hospital North West, Ethiopia. Ethiop. J. Health Dev. 2011; 24: 3-8.

16. Heil EL, Townsend ML, Shipp K, Clarke A, Johnson MD. Incidence of severe hepatotoxicity related to antiretroviral therapy in HIV/HCV co-infected patients. AIDS Res Treat. 2010; 1-4.

17. Crum-cianflone N, Collins G, Medina S et al. Prevalence and factors associated with liver enzyme abnormalities among HIV infected persons. Clin Gastroenterol Hepatol. 2010; 8: 183-191.

18. Hoffmann CJ, Charalambousa S, Thio CL et al. Hepatotoxicity in an African antiretroviral therapy cohort: the effect of tuberculosis and hepatitis B. AIDS. 2007, 21:1301-1308.

19. Lucent C, Clement KH, ANK F, Weldeji NP, Ndikvu CP. The effects of antiretroviral treatment on liver function enzymes among HIV infected out patients attending the central hospital of Yaoundé Cameron. AFRJ. CLIN. Exper. Microbiol. 2010. 11(3): 174-178.

20. Livry C, Binquet C, Sgroc C et al. Acute liver enzyme elevation in HIV-1 infected patients. HIV Clin trials. 2003; 4: 400-410.
21. Chu KM,Boulle AM, Ford N, Goemaere E, Easselmar V, Altesem GV. Nevirapine associated early hepatotoxicity: Incidence, risk factors, and associated mortality in a primary care art programmes in South Africa. PLOS ONE. 2010; 5(2): 9183.

22. Kovari H, Ledergerber B, Battegay $\mathrm{M}$ et al. Incidence and risk factors for chronic elevation of alanine amino transferase levels in HIV infected persons without hepatitis B or $\mathrm{C}$ virus co-infection. CID. 2010; 50: 502-511.

23. Lima SD, Fatima MD, Ramos H, Melo LD. Hepatotoxicity induced by antituberculosis drugs among patients co infected with HIV and tuberculosis. Cad.Saude Publica. 2012; 28: 698-708.

24. Yimer G, Aderaye G, Amogne $\mathrm{W}$ et al. Antituberculosis therapy induced hepatotoxicity among Ethiopian HIV positive and negative patients. Plos One. 2008; 3: 1-5.

25. Gisolf EH, Drezen C, Danner SA, Weel JF, Weverling GJ. Risk fact ors for hepatotoxicity in HIV infected patients receiving ritonavir and saquinavir with or without stavudine. CID. 2000; 31: 1234-1239.

26. Forrester J, Rhee MS, Mcgovern BH, Sterling RK, Knox TA, Terrin N. The association of HIV viral load with indirect markers of liver injury. J viral Hepat. 2012; 19: 200-211. 